\title{
STRATEGI KOMUNIKASI ECPAT INDONESIA UNTUK MEMERANGI PARIWISATA SEKS ANAK (PSA)
}

\author{
Dany, S.IP, M.Si \\ Anggun Putri Dewanggi I.B, S.Sos,MM \\ dany.alucard@gmail.com \\ anggun.putridewanggi@budiluhur.ac.id
}

\begin{abstract}
This study aims to find out and analyze "ECPAT's Communication Strategies In Establishing Partnerships With The Private Sector In The National Tourism Industry To Combat Child Sex Tourism". The problem formulation in this research is how ECPAT's communication strategies in establishing partnerships with the private sector in the national tourism industry to combat child sex tourism. The research method that used in this research is descriptive qualitative approaching method. Data collection were obtained through in-depth interviews with program manager of ECPAT Indonesia, also as non-participant observator in the secretariat of ECPAT Indonesia and by collecting of documentary data that supported the research. The theory that used in this research is Advocacy Communication model from the Hopkins University for Communication Programs $(C C P), U S A$. The research result showed that ECPAT Indonesia collaborated with several partners, including PHRI (Persatuan Hotel Indonesia), ASPPI (Asosiasi Pelaku Pariwisata Indonesia), Taxi Putra as transportation services, PT Angkasa Pura II and Accor Group Hotel. The collaboration was built using Advocacy Communication model from the John Hopkin, especially in mobilization and action stages, by forming the "Down To Zero" program with coalition partners.
\end{abstract}

Keywords : Establishing Partnerships, ECPAT Indonesia, Child Sex Tourism (CST)

\footnotetext{
${ }^{1}$ Ketua Peneliti, Dosen Universitas Budi Luhur 2 Anggota Peneliti, Dosen Universitas Budi Luhur.
} 


\begin{abstract}
ABSTRAK
Penelitian ini bertujuan untuk mengetahui dan menganalisis "Strategi Komunikasi ECPAT Dalam Membangun Kemitraan Dengan Sektor Swasta Dalam Industri Pariwisata Nasional Untuk Memerangi Pariwisata Seks Anak". Rumusan masalah dalam penelitian ini adalah bagaimana strategi komunikasi ECPAT dalam membangun kemitraan dengan sektor swasta dalam industri pariwisata nasional untuk memerangi pariwisata seks anak. Metode penelitian yang digunakan dalam penelitian ini adalah metode pendekatan kualitatif deskriptif. Pengumpulan data diperoleh melalui wawancara mendalam dengan manajer program ECPAT Indonesia, juga sebagai pengamat non-partisipan di sekretariat ECPAT Indonesia dan dengan mengumpulkan data dokumenter yang mendukung penelitian. Teori yang digunakan dalam penelitian ini adalah model Komunikasi Advokasi dari Hopkins University for Communication Programs (CCP), Amerika Serikat. Hasil penelitian menunjukkan bahwa ECPAT Indonesia bekerja sama dengan beberapa mitra, termasuk PHRI (Persatuan Hotel Indonesia), ASPPI (Asosiasi Pelaku Pariwisata Indonesia), Taxi Putra sebagai layanan transportasi, PT Angkasa Pura II dan Accor Group Hotel. Kolaborasi ini dibangun menggunakan model Komunikasi Advokasi dari John Hopkin, terutama dalam tahap mobilisasi dan aksi, dengan membentuk program "Down To Zero" dengan mitra koalisi.
\end{abstract}

\title{
Kata Kunci: Membangun Kemitraan, ECPAT Indonesia, Pariwisata Seks Anak (CST)
}

\section{PENDAHULUAN}

Negara Indonesia seperti yang kita ketahui merupakan salah satu negara berkembang yang memiliki berbagai macam potensi pariwisata, baik wisata alam maupun wisata budaya karena Indonesia memiliki bermacam-macam suku, adat-istiadat, dan kebudayaan serta karena letak geografis negara Indonesia sebagai negara tropis yang menghasilkan keindahan alam dan satwa. Pariwisata di Indonesia merupakan sektor ekonomi penting di Indonesia, karena telah menyumbangkan produk domestik bruto (PDB). Hal ini terjadi karena setiap turis asing menghabiskan rata-rata antara 1.100 dollar AS sampai 1.200 dollar AS per kunjungan, dan juga menyediakan kesempatan kerja untuk masyarakat Indonesia. Diperkirakan bahwa hampir 9\% dari total angkatan kerja nasional dipekerjakan di sektor pariwisata. (http://www.indonesia- 
investments.com/id/bisnis/industri-

sektor/pariwisata/item6051?, diakses tanggal 12 Februari 2017 pukul 20:34).

Namun dibalik meningkatnya geliat industri pariwisata di Indonesia, ternyata ada hal lain yang perlu dikhawatirkan. Para wisatawan asing yang berkunjung ke Indonesia ternyata tidak hanya tertarik kepada keindahan alam Indonesia tetapi mereka juga tertarik dengan wisata seks di Indonesia, dan yang lebih mengkhawatirkan kepada wisata seks anak di Indonesia. Kekhawatiran ini sesuai dengan yang dikatakan oleh Ahmad Sofyan selaku Koordinator ECPAT Indonesia. Dia mengatakan bahwa "Indonesia merupakan negara ketiga pariwisata seks anak, dibandingkan Thailand sebab sepuluh tahun yang lalu Thailand menjadi destinasi pariwisata seks anak yang dikecam banyak kalangan," saat ditemui dalam acara 'Keberpihakan Dunia Usaha dan Upaya Pencegahan Pariwisata Seks Anak', di bilangan Matraman, Jakarta Timur, Rabu, 23 Desember 2015 (http://feed.merdeka.com/article/awa $\underline{\text { s-indonesia-menjadi-lokasi-favorit- }}$ pariwisata-seks-anak-1512233.html, diakses tanggal 12 Februari 2017, pukul 20:43).

Indonesia sendiri telah menjadi salah satu negara yang menjadi tujuan wisata seks komersial, ada 7 provinsi di Indonesia yang menjadi tujuan utama para turis mencari kepuasan seksual. Provinsi itu antara lain; DKI Jakarta, Bali, Jawa Barat, Jawa Timur, Kepulauan Riau, Sumatera Utara dan Nusa Tenggara Barat (NTB). Yang memprihatinkan adalah, prostitusi yang terjadi di provinsi-povinsi tersebut melibatkan anak-anak, seperti yang dilansir dari Ahmad Sofyan, koordinator ECPAT Indonesia. "Yang terbesar memang terjadi di wilayah Batam (Kepulauan Riau), Bali dan Lombok (NTB). Batam jelas menjadi pintu masuk wisatawan, pebisnis dan para pekerja, Bali sudah bukan rahasia lagi, sementara Lombok seperti pesatnya pertumbuhan wisata Senggigi, pesat pula perputaran prostitusinya terutama yang melibatkan anakanak," (Artikel ilmiah Wanita Indonesia, Indonesia Salah Satu Tujuan Wisata Seks, 
http://www.wanitaindonesia.co.id/in

dex.php?view=viewarticle \&id=1609

0136, diakses tanggal 12 Februari 2017, pukul 21:13).

Pada sektor privat, kesadaran hukum atas eksploitasi seksual komersial anak masih sangat lemah, masih sangat minimnya kesadaran hukum para pelaku usaha di industri pariwisata nasional. Hal ini disampaikan oleh Andy Ardian, Manager Program ECPAT Indonesia pada seminar "Pariwisata Seks Anak di Destinasi Wisata: Mengukur Keterlibatan Sektor Swasta dan Perlindungan Hukum" di Gedung Joseph Wibowo Center, Universitas Bina Nusantara, Jalan Hang Lekir, Senayan, Jakarta, Selasa, 14 April 2015

(http://ecpatindonesia.org/berita/indo nesia-tujuan-wisata-seks-anak-

pelaku-usaha-jasa-pariwisata-harusproaktif-mengantisipasi/, diakses tanggal 12 Februari 2017, pukul 21:17). Menurut Andy, praktek pariwisata seks anak itu melibatkan pihak swasta di rantai industri pariwisata yang mengurusi jasa perjalanan, penginapan, transportasi dan lainnya.
Isu pariwisata seks anak merupakan salah satu isu yang harus menjadi perhatian bersama karena menyangkut berbagai pihak terutama sektor industri pariwisata. Berdasarkan hasil putusan Mahkamah Agung Republik Indonesia, ada sejumlah 46 kasus pariwisata seks anak selama 2010-2014, 40 anak perempuan dan 6 anak laki-laki dengan hanya 28 pelaku dimana 27 merupakan warga Indonesia dan 1 warga Belanda. Jumlah ini sangat kecil jika dibandingkan jumlah sebenarnya yang terjadi (http://ecpatindonesia.org/berita/bers ama-memerangi-pariwisata-seksanak/, diakses tanggal 22 Februari 2017, pukul 3.30).

Salah satu upaya agar isu PSA ini bisa mendapatkan perhatian oleh sektor swasta industri pariwisata nasional agar ikut aktif turut serta dalam memerangi isu tersebut, adalah melalui komunikasi yang dibangun oleh sebuah organisasi yang konsisten mengurusi masalah PSA. Salah satu organisasi yang peduli serta konsisten atas permasalahan PSA ini adalah ECPAT (End Child Prostitution, Child Pornography \& Trafficking Of 
Children for Sexual Purposes). ECPAT bermula pada tahun 1990, pada awalnya ECPAT merupakan suatu kampanye dalam melawan prostitusi anak di pariwisata Asia (End Child Prostitution in Asian Tourism) suatu kampanye yang dimulai di Chiang Mai, Thailand. Pada perkembangan selanjutnya, ECPAT kemudian mengubah dirinya menjadi suatu organisasi non pemerintah atau non government organization (NGO) dan mengubah singkatan namanya menjadi End Child Prostitution, Child Pornography \& Trafficking Of Children for Sexual Purposes

Kehadiran ECPAT di

Indonesia adalah untuk memastikan semua elemen masyarakat melakukan langkah-langkah serius dan sungguhsungguh dalam menangani ESKA. Salah satu misi ECPAT kepada masyarakat adalah untuk membangun dan meningkatkan kesadaran, kepedulian, sikap kritis dan partisipasi masyarakat luas; anak; dan orang muda untuk bersama memerangi ESKA (http://ecpatindonesia.org/tentangkami/, diakses 12 Februari 2017, pukul 21:49). Hal ini juga sejalan dengan salah satu prinsip komunikasi, yaitu komunikasi berlangsung dalam berbagai tingkat kesengajaan dan komunikasi memiliki tujuan (Fajar, 2009: 38-39). Komunikasi berlangsung dalam berbagai tingkat kesengajaan karena dalam berkomunikasi, komunikator memilih waktu yang tepat untuk suatu pesan, bahasa yang dipergunakan, sikap dan nilai yang harus ditampilkan, serta jenis kelompok di mana komunikasi akan dilaksanakan.

Dari uraian pada latar belakang penelitian di atas, maka judul dari penelitian ini adalah: "Strategi Komunikasi ECPAT Indonesia (End Child Prostitution, Child Pornography \& Trafficking Of Children for Sexual Purposes) Dalam Menjalin Kemitraan Dengan Sektor Swasta Pada Industri Pariwisata Nasional Untuk Memerangi Pariwisata Seks Anak (PSA)".

\section{Rumusan Masalah}

Bagaimana strategi komunikasi ECPAT Indonesia dalam menjalin kemitraan dengan sektor swasta pada industri pariwisata nasional untuk memerangi pariwisata seks anak, dan 
apakah yang dimaksud dengan pariwisata seks anak? Tujuan Penelitian Untuk mengetahui dan menganalisa strategi komunikasi yang digunakan ECPAT Indonesia dalam menjalin kemitraan dengan sektor swasta pada industri pariwisata nasional untuk memerangi pariwisata seks anak dan untuk mendapatkan pengetahuan secara mendalam tentang pariwisata seks anak

\section{TINJAUAN PUSTAKA}

\section{Komunikasi}

Everett M. Rogers \& Lawrence Kincaid (1981: 18, dalam Fajar, 2009: 32) mendefinisikan komunikasi sebagai suatu proses dimana dua orang atau lebih membentuk atau melakukan pertukaran informasi antara satu sama lain, yang pada gilirannya terjadi saling pengertian yang mendalam.

\section{Strategi Komnikasi}

Rogers (1982, dalam Cangara, 2014: 64) memberi batasan pengertian strategi komunikasi sebagai suatu rancangan yang dibuat untuk mengubah tingkah laku manusia dalam skala yang lebih besar melalui transfer ide-ide baru.

\section{Lembaga Swadaya Masyarakat}

T Tarrow (1994, dalam Budiardjo, 2008: 383) dalam bukunya Power in Movement, mengemukakan definisi gerakan sosial sebagai berikut: "Social movements are collective challenges by people with common purposes and solidarity in sustained interaction with elites, opponents and authorities (gerakan sosial adalah tantangan kolektif oleh orangorang yang mempunyai tujuan bersama berbasis solidaritas yang dilaksanakan melalui interaksi secara terus menerus dengan para elite, lawan-lawannya, dan pejabat yang berwenang)" .

\section{Sektor Swasta pada Industri}

\section{Pariwisata}

Pengertian tentang industri pariwisata, antara lainnya sebagai kumpulan dari macam-macam perusahaan yang secara bersama menghasilkan barang-barang dan jasa-jasa (goods and service) yang dibutuhkan para wisatawan pada khususnya dan traveler pada umumnya, selama dalam perjalanannya. (Yoeti, 1985: 9, dalam 
http://www.edutourism.eu.pn/6-

pengertian-industri-pariwisata.html, diakses tanggal 13 Februari 2017, pukul 22:34).

\section{Eksploitasi Seksual Komersial} Anak

ECPAT Internasional (2001, dalam Artikel Ilmiah, Eksploitasi Seksual Komersial Anak di Indonesia, Koalisi Nasional, 2008: 7) mendefinisikan Eksploitasi Seksual Komersial Anak atau disebut juga ESKA sebagai,

"Pelanggaran mendasar terhadap hak-hak anak, pelanggaran tersebut berupa kekerasan seksual oleh orang dewasa dengan pemberian imbalan kepada anak, atau orang ketiga, atau orangorang lainnya. Sederhananya anak diperlakukan sebagai objek seksual dan komersial. Ini adalah perwujudan dari kerja paksa dan perbudakan modern terhadap anak. Sebab tak jarang anak-anak dipaksa mengalami kekerasan fisik dan trauma."

\section{Pariwisata Seks Anak (PSA)}

$$
\begin{aligned}
& \text { Pariwisata Seks Anak } \\
& \text { merupakan salah satu bentuk dari } \\
& \text { praktek eksploitasi seksual komersial } \\
& \text { anak yang dilakukan oleh orang atau } \\
& \text { orang-orang yang melakukan } \\
& \text { perjalanan dari daerah, wilayah } \\
& \text { geografis atau negara asal untuk } \\
& \text { melakukan hubungan seksual dengan } \\
& \text { anak-anak (Memerangi Pariwisata } \\
& \text { Sex Anak: Tanya \& Jawab, Ecpat }
\end{aligned}
$$
Internasional, 2008: 6)

\section{Model Komunikasi Advokasi}

Model komunikasi advokasi terdiri atas enam tahapan, yakni: a. Analisis; b. Strategi; c. Mobilisasi; d. Aksi; e. Evaluasi; dan f. Kesinambungan. Model komunikasi advokasi dapat dilihat pada gambar berikut.

\section{Gambar 1.1}

\section{Model Komunikasi Advokasi}

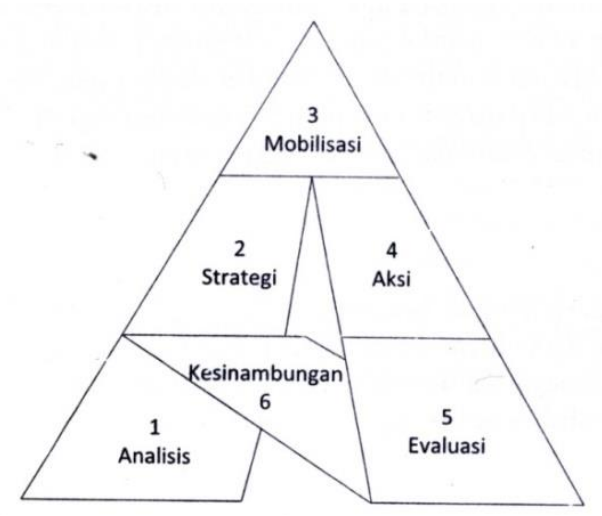


Sumber: Center for Communication

Programs John Hopkin Bloomberg School of Public Health (Cangara, 2014: 87)

Kaitannya model komunikasi advokasi yang digunakan dalam penelitian kali ini karena didalam tahapan model ini seperti (Analisis, Strategi, Mobilisasi, Aksi, Evaluasi dan Kesinambungan) ini cocok dengan penelitian yang dibuat dan juga mencakup apa yang ada di dalam penelitian kali ini.

\section{METODE PENELITIAN}

\section{Paradigma Penelitian}

Paradigma yang digunakan dalam penelitian ini adalah paradigma konstruktivisme yang mengacu pada paradigma konstruktivisme Egon Guba dan Yvonna Lincoln (Denzin \& Lincoln, 2009: 162).

\section{Pendekatan dan Metode Penelitian}

Pendekatan yang digunakan dalam penelitian ini adalah pendekatan kualitatif, penelitian kualitatif tidak mengutamakan besarnya populasi atau sampling, bahkan populasi atau samplingnya sangat terbatas. Jika data yang terkumpul sudah mendalam dan sudah bisa menjelaskan fenomena yang diteliti, maka tidak perlu mencari sampling lainnya (Kriyantono, 2006: 56).

Menurut Ardianto (2014: 60), metode deskriptif kualitatif mencari teori, bukan menguji teori; hypotesis generating, bukan hypotesis testing; dan heuristic bukan verifikasi. Ia juga mengatakan bahwa ciri khas metode deskriptif kualitatif menitik beratkan pada observasi dan suasana alamiah (natural setting).

\section{Subjek dan Narasumber Penelitian}

Dalam penelitian ini yang menjadi subjek penelitian adalah Program Manager ECPAT Indonesia, karena penelitian ini bertujuan mengetahui strategi komunikasi yang digunakan oleh ECPAT Indonesia dan mengetahui secara mendalam tentang pariwisata seks anak

Dalam penelitian ini yang menjadi narasumber penelitian. adalah Bapak Andy Ardian selaku Program Manager ECPAT Indonesia karena memiliki kapasitas untuk dapat menjelaskan secara terperinci tentang strategi komunikasi ECPAT 
Indonesia. Dalam penelitian kualitatif, dikenal beberapa metode pengumpulan data: yaitu observasi, focus group discussion, wawancara mendalam dan studi kasus (Wimmer 2000; 110; Sendjaya 1997; 32, dalam Kriyantono, 2006: 93).

\section{Validitas Data}

Dalam penelitian ini, peneliti memilih untuk menggunakan Triangulasi Metode, yaitu dengan menggunakan tiga jenis metode pengumpulan data, yaitu wawancara mendalam, observasi non partisipan, dan metode dokumenter.

\section{HASIL PENELITIAN}

ECPAT mempunyai peranan dalam memberantas masalah perdagangan anak di bawah umur, pornografi anak, dan perdagangan dengan tujuan seksual. Pada mulanya hanya merupakan perkumpulan individu, yang kemudian tergabung menjadi satu dalam ECTWT (Ecumenical Coalition on Third World Tourism). ECTWT dibentuk pertama kali di Bangkok, Thailand pada tahun 1982 untuk melakukan program penelitian mengenai dampak dari perkembangan pariwisata di kawasan Asia. Hasil dari studi tersebut dibahas dalam suatu forum International

Consultation, Kemudian dari pertemuan tersebut diputuskan untuk menggalang suatu kampanye internasional yang dikenal dengan ECPAT (End Child Prostitution in Asia Tourism).

ECPAT Indonesia adalah sebuah organisasi jaringan nasional yang bekerja bersama di lebih dari 20 organisasi di 11 propinsi di Indonesia untuk menentang Eksploitasi Seksual Komersial Anak (ESKA) Mereka berkomitmen untuk memperkuat aksi nasional dalam upaya mencegah dan menghapuskan ESKA di Indonesia dengan membangun kolaborasi bersama pihak-pihak kunci lintas sektor seperti organisasi masyarakat sipil, akademisi, badan pemerintah, sektor swasta, badan internasional dan sektor-sektor relevan lainnya. ECPAT Indonesia merupakan bagian dari ECPAT Internasional, yaitu sebuah jaringan global yang bekerja untuk menentang ESKA dengan lebih dari 84 group di lebih dari 75 negara di seluruh dunia.

ESKA, yang merupakan singkatan dari Eksploitasi Seksual Komersial Anak, merupakan suatu 
kegiatan memanfaatkan anak-anak oleh sindikat-sindikat tertentu guna dijadikan objek seksual untuk kepentingan ekonomi. Namun pada faktanya, justru anak-anak seringkali tidak merasa menjadi korban, mereka justru merasa mendapatkan keuntungan secara komersial. Kejahatan ESKA sendiri terbagi menjadi beberapa kategori, antara lain; pertama, prostitusi anak. Kedua, pornografi anak. Ketiga, perdagangan anak untuk tujuan seksual. Keempat, perkawinan anak dan kelima, pariwisata seks anak. Pariwisata seks anak yang merupakan salah satu kategori kejahatan ESKA, memiliki beberapa ciri yang mana pelakunya disinyalir merupakan orang asing atau wisatawan asing. Tentu untuk penangannya memerlukan aturan hukum internasional, tidak bisa hanya dengan menggunakan hukum negara tempat terjadinya kejahatan tersebut. Tidak diketemukannya keterlibatan langsung sektor swasta pada Pariwisata Seks Anak, menyiratkan beberapa pihak pada sektor swasta yang berperan secara tidak langsung sebagai penyalur untuk PSA. Ditambah lemahnya atau bisa juga dikatakan ketidak-pedulian perusahaan swasta penyedia jasa penginapan atau hotel, untuk mencegah terjadinya kejahatan PSA membuat kasus ini semakin marak. Kemungkinan besar sektor swasta pada industri pariwisata tidak ingin terlibat lebih jauh, karena akan mempengaruhi image industri mereka. Selain sektor swasta, yang tidak ingin terlibat jauh dalam permasalahan PSA, ternyata hal ini juga ikut terbawa pada sektor pemerintahan. Khususnya pada badan yang mengurusi pariwisata Indonesia, yaitu Kementerian Pariwisata.

Strategi yang dilakukan oleh ECPAT Indonesia untuk bisa menjalin kemitraan dengan sektor swasta untuk memerangi PSA adalah dengan menjalin kerjasma dengan PHRI (Persatuan Hotel dan Restoran Indonesia) agar isu PSA semakin lebih dikenal dan dipedulikan oleh hotel-hotel yang ada di Indonesia. Strategi berikutnya adalah melakukan kampanye untuk menginformasikan kepada publik tentang aktivitas eksploitasi seksual komersial anak, khusus untuk kampanye ini, pihak ECPAT Indonesia menjalin 
kemitraan dengan Angkasa Pura II agar informasi tersebut dapat langsung diterima oleh para wisatawan. Strategi ECPAT Indonesia berikutnya yang dilakukan untuk memerangi pariwisata seks anak di Indonesia adalah melakukan komunikasi serta menjalin kerjasama dengan Asosiasi Pelaku Pariwisata Indonesia (ASPPI) yang terdiri dari pelaku-pelaku usaha yang memiliki kepedulian dalam membangun dunia wisata di Indonesia. ECPAT Indonesia menjalin kerjasama dengan jasa transportasi Taksi Putra, tujuan dari kerjasama ini adalah dengan cara memberikan pelatihan kepada para supir taksi agar memahami dan dapat turut menanggulangi isu-isu PSA. Media yang digunakan ECPAT Indonesia dalam menyampaikan isu PSA kepada publik antara lain brosur, flyer, buku saku, poster, sign board, standing banner, website dan media sosial (Facebook, Twitter, Instagram, Youtube).

Hasil penelitian dengan yang telah dibahas untuk mengetahui dan menganalisa strategi komunikasi yang digunakan ECPAT Indonesia dalam menjalin kemitraan dengan sektor swasta pada industri pariwisata nasional untuk memerangi pariwisata seks anak di Indonesia dan untuk mendapatkan pengetahuan secara mendalam tentang pariwisata seks anak. Adapun pembahasan peneliti terkait analisa strategi yang digunakan ECPAT Indonesia mengacu pada model Komunikasi Advokasi yang diperkenalkan oleh Center for Communication Program (CCP) John Hopkins University, USA yaitu langkah analisis dan strategi, langkah mobilisasi dan aksi, langkah evaluasi dan kesinambungan dalam menjalankan program "Down To Zero".

\section{KESIMPULAN}

Melihat permasalahan PSA dalam skala nasional, ECPAT Indonesia berusaha menjalin kemitraan dengan sektor swasta pada industri pariwisata nasional untuk memerangi pariwisata seks anak di Indonesia. Strategi yang digunakan ECPAT Indonesia mencakup beberapa langkah, antara lain :

\section{Langkah Analisis dan Strategi}

Berdasarkan hasil analisis yang telah dilakukan, ECPAT Indonesia melihat 
bahwa kasus eksploitasi seksual komersial anak merupakan masalah yang sangat besar. Pada kenyataanya kasus PSA yang terjadi di Indonesia tidak hanya terjadi pada destinasi tujuan wisata saja, namun juga terjadi secara daring. Lebih buruknya lagi, baik dari segi pemerintah ataupun masyarakat belum melihat kasus ini sebagai kasus yang penting dan memiliki tingkat urgensi tinggi.

Berdasarkan hasil analisa yang telah ditemukan, ECPAT Indonesia akhirnya memfokuskan diri pada upaya pengurangan tindak ESKA melalui strategi "Down To Zero". Program ini tidak hanya diterapkan di Indonesia, namun juga di 11 negara lainnya. Program "Down To Zero" sebagai strategi dijalankan oleh ECPAT Indonesia.

\section{Langkah Mobilisasi dan Aksi}

Guna mendukukung serta memperkuat program "Down To Zero" yang dijalankan oleh ECPAT Indonesia dalam rangka menyikapi fenomena PSA yang telah terjadi, mereka membentuk aliansi dengan beberapa lembaga yang memiliki visi misi yang sama seperti, PLAN International dan Terre des Hommes
Netherland. ECPAT Indonesia juga menyasar strategi "Down To Zero" kepada pihak eksekutif, Sektor private dan Transportasi. Aksi yang dilakukan oleh ECPAT Indonesia dalam mempertahankan isu yang telah difokuskan sebelumnya, yaitu mengenai kasus ESKA di Indonesia dengan skema "Theory Of Chage". Skema ini dibuat untuk menyasar kepada empat sasaran yaitu, Pemerintah termasuk Kepolisian, sektor privat di dunia pariwisata, masyarakat/ komunitas dan paling utamanya adalah anak. Dalam mempertahankan perhatian beberapa pihak yang telah disebutkan terhadap isu ESKA dan PSA yang terjadi di Indonesia, maka ECPAT Indonesia memberlakukan pola komunikasi seperti audiensi serta menawarkan kerjasama.

\section{Langkah Evaluasi dan}

\section{Kesinambungan.}

Program "Down To Zero" harus senantiasa dievaluasi secara seksama, mekanisme evaluasi yang dilakukan melalui metode Reporting. Kegiatan pelaporan ini diberlakukan secara kwartal maupun semester. Dalam menjalankan fungsi evaluasi karena 
ECPAT Indonesia beraliansi dengan lembaga lain yang memiliki concern sama seperti Plan International dan Terre des Hommes dengan melakukan switching sebagai evaluator setiap program yang dilakukan.

Memelihara kesinambungan program yang disosialisasikan ECPAT Indonesia pada keempat target sasaran program bukan hal yang mudah, apalagi memelihara kesinambungan pada sektor privat khusus di bidang sektor wisata. Lain halnya dengan pemerintah, kesinambungan program antara pemerintah dan ECPAT Indonesia sendiri lebih terjaga karena kedua belah pihak telah memiliki MOU yang jelas yang dapat digunakan untuk membesarkan isu ini.

Budiardjo, Miriam. 2013. DasarDasar Ilmu Politik. Jakarta: PT. Gramedia Pustaka Utama.

Cangara, Hafied. 2014. Perencanaan \& Strategi Komunikasi. Jakarta: PT. RajaGrafindo Persada.

Denzin, Norman K \& Yvonna S. Lincoln. 2009. Handbook of Qualitative

Research, terj. Dariyatno, dkk. Yogyakarta: Pustaka Pelajar.

Fajar, Marhaeni. 2009. Ilmu Komunikasi: Teori \& Praktik. Yogyakarta: Graha Ilmu.

Kriyantono, Rahmat. 2006. Teknik Praktis Riset Komunikasi. Jakarta: Kencana

Prenada Media Group.

\section{Artikel dan Jurnal}

Koalisi Nasional Penghapusan Eksploitasi Seksual Komersial Anak. 2008.

\section{DAFTAR PUSTAKA}

Eksploitasi

Seksual

Komersial Anak di Indonesia.

Buku

Indonesia: RESTU Printing. 
ECPAT Internasional. 2008. $\quad$ http://www.edutourism.eu.pn/6-

Memerangi Pariwisata Seksual Anak: pengertian-industri-pariwisata.html

Tanya \&

Jawab. Indonesia: RESTU

Printing.

\section{Situs Internet}

http://www.indonesia-

investments.com/id/bisnis/industri-

$\underline{\text { sektor/pariwisata/item6051 }}$

http://feed.merdeka.com/article/awas

-indonesia-menjadi-lokasi-favorit-

pariwisata-seks-anak-1512233.html

http://www.wanitaindonesia.co.id/in

dex.php?view=viewarticle \&id=1609

$\underline{0136}$

http://ecpatindonesia.org/berita/indon esia-tujuan-wisata-seks-anak-pelakuusaha-jasa-pariwisata-harus-proaktifmengantisipasi/

http://ecpatindonesia.org/tentang-

kami/

http://ecpatindonesia.org/berita/bersa

$\underline{\text { ma-memerangi-pariwisata-seks-anak/ }}$ 